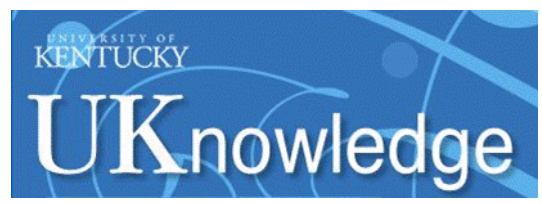

University of Kentucky

UKnowledge

\title{
Violence and Women's Mental Health: The Impact of Physical, Sexual, and Psychological Aggression
}

\author{
Carol E. Jordan \\ University of Kentucky, carol.j@uky.edu \\ Rebecca Campbell \\ Michigan State University \\ Diane R. Follingstad \\ University of Kentucky, follingstad@uky.edu
}

Follow this and additional works at: https://uknowledge.uky.edu/crvaw_facpub

Part of the Criminal Law Commons, Criminology and Criminal Justice Commons, Family Law

Commons, Law and Gender Commons, Law and Psychology Commons, and the Social Work Commons

Right click to open a feedback form in a new tab to let us know how this document benefits you.

\section{Repository Citation}

Jordan, Carol E.; Campbell, Rebecca; and Follingstad, Diane R., "Violence and Women's Mental Health: The Impact of Physical, Sexual, and Psychological Aggression" (2010). CRVAW Faculty Journal Articles. 7. https://uknowledge.uky.edu/crvaw_facpub/7

This Article is brought to you for free and open access by the Center for Research on Violence Against Women at UKnowledge. It has been accepted for inclusion in CRVAW Faculty Journal Articles by an authorized administrator of UKnowledge. For more information, please contact UKnowledge@lsv.uky.edu. 
Violence and Women's Mental Health: The Impact of Physical, Sexual, and Psychological Aggression

Digital Object Identifier (DOI)

http://dx.doi.org/10.1146/annurev-clinpsy-090209-151437

Notes/Citation Information

Published in Annual Review of Clinical Psychology, v. 6, p. 607-628. 


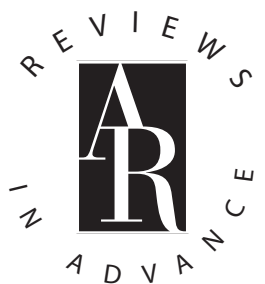

\title{
Violence and Women's Mental Health: The Impact of Physical, Sexual, and Psychological Aggression
}

\author{
Carol E. Jordan, ${ }^{1}$ Rebecca Campbell, ${ }^{2}$ \\ and Diane Follingstad ${ }^{3}$ \\ ${ }^{1}$ Center for Research on Violence Against Women, University of Kentucky, Lexington, \\ Kentucky 40506-0059; email: carolj@uky.edu \\ ${ }^{2}$ Department of Psychology, Michigan State University, East Lansing, \\ Michigan 48824-1116; email: rmc@msu.edu \\ ${ }^{3}$ Department of Psychiatry, University of Kentucky, Lexington, Kentucky 40509; \\ email: Follingstad@uky.edu
}

Annu. Rev. Clin. Psychol. 2010. 6:1.1-1.22

The Annual Review of Clinical Psychology is online at clinpsy.annualreviews.org

This article's doi:

10.1146/annurev-clinpsy-090209-151437

Copyright (C) 2010 by Annual Reviews.

All rights reserved

$1548-5943 / 10 / 0427-0001 \$ 20.00$

\section{Key Words}

intimate partner violence, sexual assault, stalking, psychological aggression

\begin{abstract}
The reach of violence against women (VAW) has been profoundly felt by women across the United States and around the globe. VAW has been documented for decades as a legal and social justice problem, but as illuminated in this review, it is also a substantial mental health concern. A full understanding of the phenomenon must include discussion of how often it occurs, in what forms, and to whom. This review defines violence against women in its variant forms and examines the literature on the mental health effects associated with these abuse experiences. The effectiveness of the mental health system's response to the complex needs of women suffering battering, rape, stalking, and psychological aggression is also examined. The future of research and the important role of the discipline of psychology in the future of this field of study is discussed.
\end{abstract}




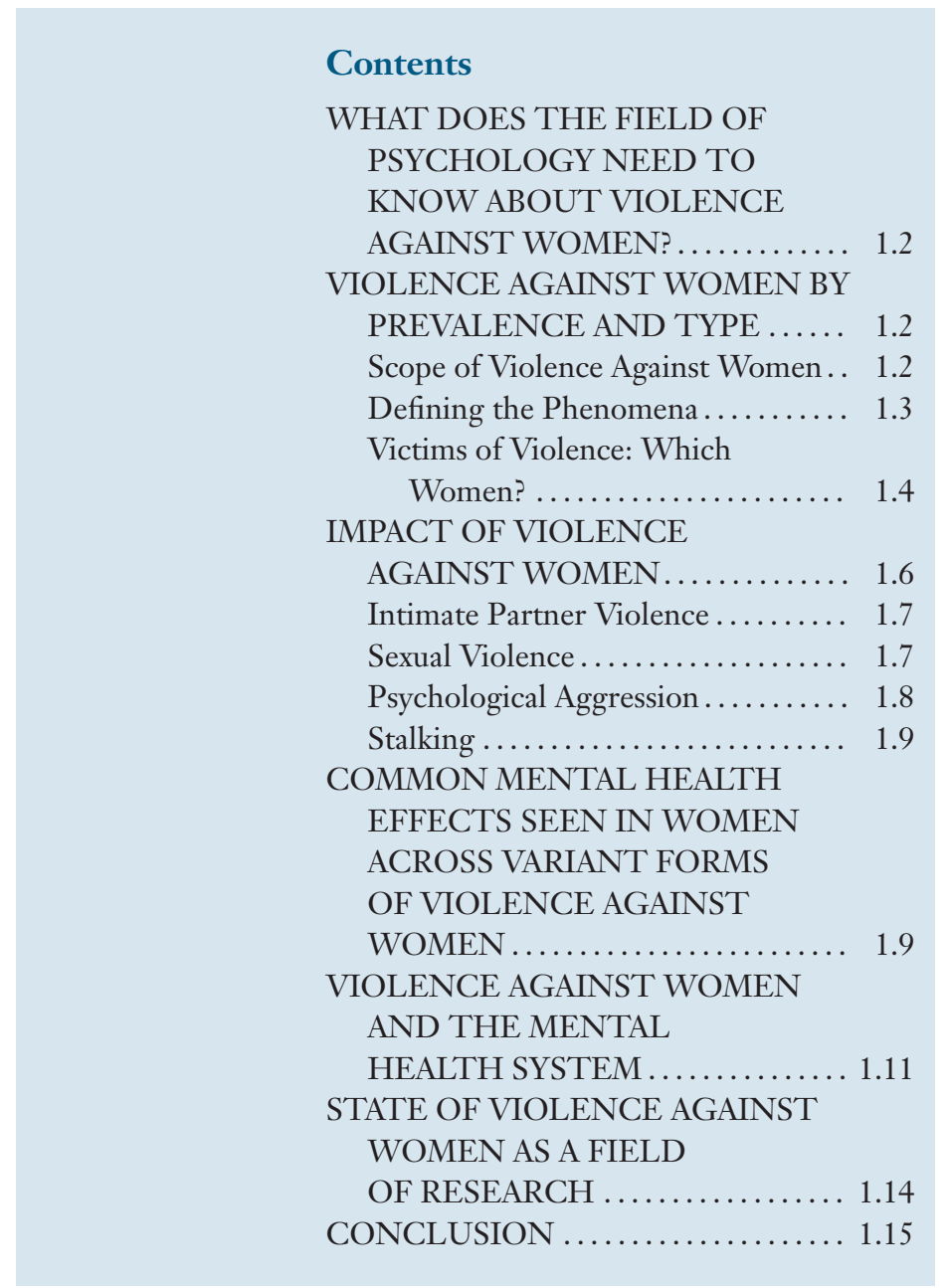

VAW: violence against women

IPV: intimate partner violence

NVAWS: National

Violence Against

Women Survey

\section{WHAT DOES THE FIELD OF PSYCHOLOGY NEED TO KNOW ABOUT VIOLENCE AGAINST WOMEN?}

The reach of violence against women (VAW) has been felt by women across the United States and around the globe. VAW has been documented for decades as a legal and social justice problem, but as illuminated in this review, it is also a substantial mental health concern. Research suggests that the impact of intimate partner violence (IPV), stalking, rape, and psychological aggression on women's mental health is robust, and in fact most forms of major nonorganic mental distress and disorder have been associated with these forms of violence. Although associations are documented, women do not experience these negative psychological health effects in the same time frame or to the same extent. The complexity of postassault responses is affected by a variety of factors and made more complex yet by the fact that most women suffering violence experience multiple forms of abuse over their lifetimes. Whether providing clinical care or researching these clinical phenomena, psychologists have a key role to play in addressing VAW and its aftermath.

\section{VIOLENCE AGAINST WOMEN BY PREVALENCE AND TYPE}

\section{Scope of Violence Against Women}

To date, three nationally representative prevalence surveys on VAW have been conducted in the United States. The National Family Violence Survey reported that $25 \%$ of American couples had experienced at least one incident of violence in the course of their relationship (Straus et al. 1980, Straus \& Gelles 1990); the National Crime Victimization Survey sponsored by the Bureau of Justice Statistics revealed that nearly 5 million violent victimizations are experienced by females over the age of 12 every year (Bachman \& Saltzman 1995); and the National Violence Against Women Survey (NVAWS) found that $52 \%$ of women reported being physically assaulted and $18 \%$ reported being victims of rape or attempted rape during their lifetimes (Tjaden \& Thoennes 1998). Studies show that every year in the United States, approximately $8 \%$ of women experience physical abuse by a partner (Plichta 1996) and that more than three out of every 100 , or 1.8 million women, suffer a severe form of physical assault (Straus \& Gelles 1990). In a review, most prevalence studies assess "rape" or "sexual assault" and find that $14.8 \%$ to $36.1 \%$ of women have experienced these forms of violence in their adult lifetimes (Bachar \& Koss 2001). A meta-analysis of stalking studies revealed rates of stalking reaching $23.5 \%$ among U.S. women (Spitzberg et al. 1998). Although national 
prevalence rates of psychological maltreatment are not readily available, some indication can be derived from evidence that this form of abuse routinely co-occurs with physical and sexual violence (Dutton et al. 1999, Follingstad et al. 1990). A growing literature also highlights the prevalence of violence against women, and in some cases elevated risk of abuse forms, among women across races and ethnicities (Aldaronda et al. 2002, Bent-Goodley 2001, Kasturirangan et al. 2004, Xu et al. 2001).

\section{Defining the Phenomena}

VAW is best understood not as a singular act or form of abuse, but rather as the aggregate of physically, sexually, and psychologically abusive behaviors directed by one partner against another (Jordan et al. 2004). VAW has now been documented to occur in multiple forms, including physical assault, sexual assault, stalking, and psychological aggression (Tjaden \& Thoennes 1998).

Physical violence has been defined to include behaviors such as pushing, shoving, slapping, hitting, kicking, biting, choking, burning, the use of weapons, or other acts that result in injury or death to a victim (Crowell \& Burgess 1996). Multiple terms are used to refer to sexual VAW, each having a slightly different meaning. Although there is variability across federal, state, and tribal statutes, most laws typically define "rape" as an act of penile/vaginal penetration committed by some degree of force or the threat of force (Berger et al. 1988). "Sexual assault" is a more inclusive term that refers to acts of unwanted sexual penetration or touch committed by the use of force, threat of force, or when the victim was incapacitated or otherwise unable to provide consent (Koss \& Achilles 2008). The Centers for Disease Control and Prevention (Basile \& Saltzman 2002) and the World Health Organization (Jewkes 2002) prefer the term "sexual violence," which includes sexually violating behaviors (e.g., noncontact acts) that may not meet legal thresholds as a crime, but nevertheless could have detrimental impact on individuals' well-being.
The empirical literature has taken several approaches to defining stalking. In 1993, the National Institute of Justice published a Model Anti-Stalking Code that defined stalking as a course of conduct that is directed at a particular person, causes the victim to fear injury or death, and would cause the "reasonable" person the same or similar type of fear (Nat. Criminal Justice Assoc. 1993). The Model Code and statutes across the country patterned after the Code pose a two-prong test for stalking definitions: the first related to the behavior and intent of the defendant (the defendant must know, or should know, that his or her conduct would place the victim in fear), and a second related to the fear or distress experienced by the victim (the victim must feel serious alarm, annoyance, or intimidation, or be emotionally distressed) (Jordan et al. 2000).

In the behavioral science literature, stalking definitions range from those that use narrow legal definitions (e.g., Tjaden \& Thoennes 1998) to those that operationalize stalking with a list of behaviors both in and outside more narrowly construed statutory language. The more narrow definitions are often found in studies intended to inform criminal justice policy and statute revision, whereas broader definitions attempt not just to define the criminal conduct of stalking, but also to capture the broader context of the victim's experience. Fisher's work is an exemplar of the latter, as she characterizes two common types of behaviors experienced by stalking victims, including "approach" (e.g., telephone calls or other methods to attempt to contact) and surveilling the victim (e.g., waiting outside workplaces or residences, following, driving by where a victim is located, or using other people to access additional information about the victim) (Fisher 2001).

The degree to which victims themselves define a set of behaviors as stalking has also been empirically studied. The implication of this research question is significant, for if victims fail to define their experience as stalking victimization, they may also be less inclined to seek appropriate legal aid or to take cautionary steps to protect themselves (Jordan et al. 2007). A 
number of studies have identified factors that influence victims' definition of their experience as stalking. For example, Tjaden and colleagues (2000) found that younger and more highly educated victims, victims stalked by current or former intimates, and victims whose stalking experience included an approach or overt attempt to contact were more likely to define the experience as stalking. Jordan and her colleagues (2007) found that victims experiencing multiple types of behaviors as part of the stalking were more likely to define their experience as stalking, as were those who experienced fear as a result of the incident(s).

Of all of the forms of VAW, psychological abuse is the most difficult to validly and reliably define (Follingstad 2007). Physical and sexual assault, as to a lesser extent stalking, have physical parameters that define when a violent action occurs, and there is little controversy as to whether the action has taken place. Even among mental health professionals, strong consensus exists only at the extreme end of the psychologically aggressive continuum (Follingstad \& DeHart 2000), and laypersons do not consistently overlap with mental health professionals in their judgments of psychological actions as "abusive" or as to ratings of severity (Follingstad et al. 2004). In addition, psychological aggression ranges from boorish and inept relationship behavior through interpersonal terrorism, and there currently is no gold standard for determining when the threshold of "psychological abuse" has been reached in a particular relationship. Different from other forms of VAW, psychological actions may require several components to concur for the behavior to be labeled as abus": (a) some type of objective consensus that the action in and of itself constitutes abuse; (b) some determination that the initiator intended maltreatment; $(c)$ the perception of the recipient (that would include an idiosyncratic analysis incorporating context and relationship history); and ( $d$ ) a determination that the action possesses the potential to psychologically harm the recipient. In this regard, Murphy \& Cascardi (1993, p. 105) offered a definition that appears to incorporate most of the components when they claimed that psychological abuse is a nonphysical form of abuse that "... consists of coercive or aversive acts intended to produce emotional harm or threat of harm."

Although not enough knowledge has been developed about more normative psychological aggression (that would be viewed by recipients as within boundaries of more typical and nonharmful conflict), a number of dimensions appear across existing measures and writings to at least suggest behaviors for which most people, lay and professional, would consider abusive. Maiuro (2001) organized the concept of psychological abuse around four impacts that the actions would be designed to accomplish: (a) "Denigrating damage to partner's self-image or esteem"; (b) "Passive-aggressive withholding of emotional support and nurturance"; $(c)$ "Threatening behavior, explicit and implicit"; and $(d)$ "Restricting personal territory and freedom."

Maiuro (2001, p. x) concluded, "The 'best' classification schema (i.e., that which is most explanatory, predictive, or useful in terms of intervention) has yet to be determined." Future research will be necessary to determine whether omissions of behavior or extremely subtle actions can be reliably measured as a form of psychological abuse, whether a pattern or more frequent occurrence would be required for particular behaviors to reach a threshold of "abuse," which component of psychological aggression would be weighted more heavily if data conflicted, whether problematic relationship behavior can be distinguished from actions considered abusive, and whether the presence of psychological abuse in combination with other forms of IPV qualitatively changes its impact.

\section{Victims of Violence: Which Women?}

The demographic variable that most consistently demonstrates an association for women with IPV, sexual assault, and stalking is age. Most research on VAW that includes age indicates that younger women are more at risk than older women (e.g., Bachman \& Saltzman 1995, O'Donnell et al. 2002). The highest 
percentage of stalked women falls in the 1624 age range, and the least likely women to be stalked are 55 and above (Greenfeld et al. 1998). Markward (1996) specifically investigated sexual abuse within physically abusive relationships and reported younger women to be more at risk for this additional form of IPV. Because age has been consistently reported as a significant demographic, numerous studies on IPV have limited their sample to women between the ages of 18 and approximately 50 as the upper delimiter (e.g., Smith et al. 2002). What has not been fully determined is whether this demographic poses more of a risk for young women because their partners are young (and therefore more likely to be aggressive) (e.g., Markward 1996), whether their age places them in a position of less power and control, whether they are likely to have young children (e.g., Weinbaum et al. 2001) and thus limited options, or whether there are greater disparities between their age and their partner's age, influencing power relationships (Jones \& Ferguson 2009). Regarding sexual assault, Tjaden \& Thoennes (1998) stated that "rape is a crime committed primarily against youth," although participants in their study were asked to report on childhood sexual assault as well as adult sexual assault experiences. Including data across the lifespan resulted in $54 \%$ of the respondents reporting sexual assaults before the age of 18 .

The cluster of demographics that combine to reflect a person's socioeconomic status (SES) (income, education, and occupation) have been found to be associated with VAW, although not always consistently across all three indicators and not always consistently across studies. U.S. samples (e.g., Tjaden \& Thoennes 2000) as well as cross-cultural samples (e.g., Gauge \& Hutchinson 2006) have reported this association regarding IPV, although a few studies have not (e.g., Fiol \& Perez 2004). O'Donnell et al. (2002) concluded that the literature assessing the impact of education with VAW was inconclusive, and employment status has not been totally consistent in its relationship to VAW, but higher income appears to be fairly solidly associated with less risk of IPV. Regarding psycho- logical abuse, there was a significant relationship between both income and education and the amount of experienced psychological maltreatment among the women in Follingstad's (2009b) national sample who reported on these behaviors in their worst cohabiting relationships. Similar to physical and sexual IPV, women with more education and higher income reported receiving less psychological aggression. Logan et al. (2006b) reviewed the relationship of sexual assault (non-IPV) with SES and reported that women in lower SES brackets were seven times more likely to have been a victim than were women in the highest income ranges. The relationship of stalking with SES has not been clearly delineated, although the general consistency of these findings for other forms of VAW would suggest a significant relationship. It is important to note, however, that all forms of VAW occur across the socioeconomic spectrum (e.g., Fiol \& Perez 2004).

When race and ethnicity are included with assessed demographics, the typical comparison contrasts Whites with African Americans on their experience of IPV. Although statistical differences have been found, the racial group considered more at risk for IPV has varied over the studies (e.g., Greenfeld et al. 1998, Smith et al. 2002), and researchers who have controlled for SES when comparing these groups find that racial differences are no longer significant identifiers as to which group is more at risk (Tjaden \& Thoennes 2000). However, when larger samples of women allow for comparisons with other racial and ethnic groups, both physical assault and sexual assault are reported at different rates (Tjaden \& Thoennes 1998). Native American and Alaska Native women reported the highest rates of rape and physical assault, which may be because some risk factors associated with victimization, such as poverty and alcohol use, are particularly prevalent in Native populations (Koss et al. 2003, Yuan et al. 2006). In addition, Native women face culturally specific risk factors. European colonization and resulting historical traumas (e.g., forced removals from homes, disrupted family structure due to forced foster care or 
boarding school, etc.) may make Native women particularly vulnerable to violence (Bubar \& Thurman 2004, Yuan et al. 2006). By contrast, Tjaden \& Thoennes (2000) documented that women of Asian/Pacific Islander descent had the lowest reported rates of rape and physical abuse. Yoshihama (1999, 2000) noted that these standardized assessments rarely capture socio-cultural differences in definitions of violence, and specific forms of abuse that are particular to Asian women's experiences (e.g., being doused with liquid) are not measured. As a result, Yoshihama and other scholars have argued that magnitude of violence against Asian women is likely underestimated. In addition, Tjaden \& Thoennes (1998) contrasted Hispanic with non-Hispanic women and found that Hispanic women were less likely to report these forms of VAW. Their study did not find racial differences among women who divulged that they had been stalked in the past. Follingstad (2009a) did not find racial differences among women reporting being the recipient of psychologically abusive behaviors in a sample that was representative of American census data.

Marital status seems to be a potential factor for IPV and stalking. Specifically, being separated/divorced from the man appears to be a more dangerous time for women who report higher rates of battering and being stalked (e.g., Greenfeld et al. 1998). Also, women who were living alone who were not married to their partner also reported higher battering rates than did married women (e.g., O'Donnell et al. 2002). Because many studies involving sexual assault variables are conducted on college populations, there does not seem to be much information regarding marital status and this form of VAW. However, because of the relationship of younger age with sexual victimization, and the fact that nonmarried women are likely to live alone, an association between marital status and sexual assault is probable. In contrast, the national sample in Follingstad's (2009b) study reported both higher frequencies and worse effects from psychological abuse if they were married as opposed to cohabiting in the worst relationship about which they were reporting.
No other major demographics have been consistently associated with VAW, most likely because research studies have collected their data using a diverse range of sampling sources (e.g., shelter women, community women, women whose partner was arrested for IPV, population-based samples, different ethnic groups, and dating versus married samples). To clarify whether other demographics are actually not related to experiencing VAW, and to prevent potentially erroneous conclusions through abstracting associations of demographics with violence across highly disparate studies, future research is needed that would sample across the range of sources listed above using the same measurement and design strategies to provide reliable comparison data. The results from that project would facilitate interpretation of data from more discrete subsequent studies with narrow samples.

\section{IMPACT OF VIOLENCE AGAINST WOMEN}

In addition to documenting the size of the problem of VAW, research makes clear the detrimental impact of these crimes (for review, see Logan et al. 2006b). Studies exploring the physical health effects of violence describe victimization as a major health problem (e.g., Coker et al. 2000), and broader negative effects of VAW are felt at family/friend and societal levels through secondary victimization, elevated fear of crime, economic costs, and other indirect costs that impair quality of life (Crowell \& Burgess 1996). The impact on women's mental health of IPV, stalking, rape, and psychological aggression are also robust (Briere \& Jordan 2004), and in fact, most forms of major nonorganic mental distress and disorder have been associated with the interpersonal victimization of women. Parenthetically, this review does not address what are now documented as high rates of victimization among women with major thought disorders (Goodman et al. 2001) because research has not suggested a causal relationship between victimization and psychoses among this unique and vulnerable population (Logan et al. 2006b). 


\section{Intimate Partner Violence}

In the area of IPV, rates of depression and anxiety appear to be higher for battered versus nonbattered women. Plichta (1996) found that $31.9 \%$ of women who reported IPV also reported a diagnosis of depression or anxiety disorder compared to $14 \%$ of women without victimization. Other studies have also documented anxiety (Gleason 1993, Kemp et al. 1995) and depression (Campbell et al. 1995, Plichta \& Weisman 1995) in intimately assaulted women. IPV has also been associated with posttraumatic stress (Kilpatrick et al. 1997), with one study finding that $84 \%$ of women seeking treatment for battering were diagnosed with posttraumatic stress disorder (PTSD) (Kubany et al. 2000). Studies also find dissociation (Briere et al. 1997), somatization (Ullman \& Brecklin 2003), cognitive disturbance such as hopelessness and low self-esteem (Janoff-Bulman 1992), and suicidality (Thompson et al. 2002) in victims of IPV. In addition to these mood, affective, anxiety, and related disorders, substance abuse has also been associated with IPV. Alcohol consumption rates have been estimated to be about five times greater among victims of IPV than among the general population of women (Grant et al. 1994). In an exemplar study from a sample of women from community health clinics, $46.4 \%$ of those reporting partner violence also reported current drug or alcohol abuse compared to $15.3 \%$ of women not reporting victimization (McCauley et al. 1995). In addition to a correlative relationship, the presence of substance abuse in the context of IPV also appears to have other effects. For example, in a study of homicide cases involving IPV, offender drug abuse appeared to increase femicide risk (Campbell et al. 2003).

\section{Sexual Violence}

With respect to sexual violence, many victims experience shock, fear, agitation, confusion, and social withdrawal immediately postassault (Herman 1992). Some may also endure flashbacks, sleeping problems, and emotional detachment, which are symptoms consistent with PTSD (Koss et al. 2003). Indeed, PTSD is the most common mental health sequelae of sexual violence. A recent review of the literature on the psychological impact of sexual assault by Campbell et al. (2009) found that $7 \%-65 \%$ of women with a lifetime history of sexual assault develop PTSD. The study on the low end of the range was an outlier, with most studies reporting rates in the $33 \%-45 \%$ range.

In addition to PTSD, the review found that many sexual victimization survivors (13\%$51 \%)$ meet diagnostic criteria for depression. Most sexual assault victims develop fear and/or anxiety (73\%-82\%), and $12 \%-40 \%$ experience generalized anxiety. Approximately 13\%-49\% of survivors become dependent on alcohol, while $28 \%-61 \%$ may use other illicit substances. It is not uncommon for victims to have suicidal ideation $(23 \%-44 \%)$, and $2 \%-19 \%$ may attempt suicide. For most sexual assault survivors, these psychological distress symptoms decline within the first few months postassault, but it is not uncommon for women to continue to experience emotional distress for up to two years postassault (Koss \& Figueredo 2004).

Not all survivors of sexual violence experience these negative psychological health effects to the same extent (Campbell et al. 2009). Most studies have not found racial/ethnic differences in postassault psychological distress; however, a study of intimate partner sexual assault victims found that Hispanic women had significantly higher levels of PTSD than did African American and Caucasian women (McFarlane et al. 2005). With respect to victims' age, Campbell et al. 2009) reported that findings have been mixed. Many of the earliest studies on this topic found that older survivors experience increased depression and general trauma, but more recent work suggests no relationship between age and distress. The relationship between education and postassault distress is murky: Some recent studies have found that lower educational levels are associated with higher PTSD and suicidality, but an equivalent number of studies have found no effect of education on distress levels.
PTSD: posttraumatic stress disorder 
Numerous studies have investigated how characteristics of the assault itself impact victims' postassault psychological distress (see Campbell et al. 2009 for review). With respect to victim-offender relationship, most studies have found that experiencing rape perpetrated by a stranger is not associated with differential levels of postrape symptomatology, but some studies have reported that surviving stranger rape was associated with increased PTSD. Sexual assault by a partner has been found to be a significant predictor of PTSD, although when compared to other types of assailants, there was no difference in depression or anxiety. The findings in the literature are equivocal as to whether injury incurred as a result of sexual assault is related to postassault PTSD, depression, and anxiety. Most examinations of postrape distress have not found an effect for weapon use, and results remain mixed as to whether degree of force used contributes to higher postassault distress levels.

\section{Psychological Aggression}

Although many articles report that deleterious effects have been identified as a result of being the target of psychological aggression, the subjective nature of the experience, the occurrence of it within interpersonal interactions and relationship contexts, the frequent co-occurrence of physical violence, and problematic measurement all combine to reduce certainty as to the impact of these actions. Although it is highly likely that serious forms of psychological abuse (e.g., higher frequency, longer doses, particular types) would impact women's mental health, this field of inquiry is still significantly hampered by measurement difficulties that limit strong conclusions at this time (see Follingstad 2007).

When trying to understand the outcome of experiencing psychological abuse, a major consideration is the fact that there are diverse forms of psychological maltreatment with apparently dissimilar aims. For example, based on Maiuro's (2001) framework of major psychological aggression dimensions (see above), causal sequences from the psychological actions to mental health outcomes are typically hypothesized as follows: (a) denigration of one's partner is intended to result in damage to selfesteem/self-concept, likely leading to depression or anxiety; $(b)$ withholding affection and nurturance is aimed at damaging self-esteem but is also a manipulative ploy to produce submissiveness, probably leading to depression, learned helplessness, and/or a passive personality style; $(c)$ threatening actions are intended to frighten/intimidate, thus leading to anxiety, compliance, and passivity; and $(d)$ restriction intends to control the partner's actions, potentially leading to depression, passivity, and lack of sociability.

A review of the outcome literature on psychological abuse to date suggests what is known and not known as to its effects (Follingstad 2009a). Lending some support to the above outcome models, the variable most studieddepression-appears to have relatively good support for depressive symptoms occurring with increasing psychological aggression, but studies using clinical levels of depression as a threshold for mental health impact did not show a significant relationship. Also complicating the picture, physical and psychological aggression take turns being the more predictive variable or even the only contributing source for depression. Examining anxiety as an outcome variable has resulted in contradictory findings, although this would not be unexpected considering that some forms of psychological abuse are not intended to produce fright or anxiety, whereas others are used specifically for that purpose (e.g., direct threats to harm/kill the woman). Separating out anxiety as a clinical concept from "fear" regarding one's safety may also clarify when and how these emotional states are impacted by psychological abuse. Mixed results were found for the impact of psychological abuse on self-esteem, although mediating variables seemed important (and therefore encouraging) for understanding this relationship. If one considers physical health outcomes as potentially impacted via the psychological toll of being the victim of psychological 
abuse, this relationship still requires disentangling through the establishment of medi$\mathrm{cal} /$ psychological models that can be tested to explain why certain health problems are associated with physical versus psychological aggression and what would mediate/moderate these relationships. Other mental health symptoms that could be investigated further as outcome variables, but do not have enough corroboration in the research literature to form conclusions, are guilt/shame, substance use/abuse, stress, cognitive impairment, and personality traits.

\section{Stalking}

Anxiety, depression, sleeplessness, anger, intense stress, and trauma symptoms have all been associated in the literature with the experience of stalking (Davis et al. 2002, Pathé \& Mullen 1997). Although stalking may lead to physical violence (in fact, research suggests that intimate partner stalkers are more likely to be violent than are stalkers of nonintimates; Palarea et al. 1999), it is the fear of violence or death and the protracted and unpredictable pattern of stalking that appears to be associated most directly with deleterious mental health effects (Davis et al. 2002).

\section{COMMON MENTAL HEALTH EFFECTS SEEN IN WOMEN ACROSS VARIANT FORMS OF VIOLENCE AGAINST WOMEN}

Mental health complications associated with VAW for women are frequently documented irrespective of the type of violence experienced. Across populations of women experiencing IPV, sexual assault, stalking, or psychological abuse, anxiety has been targeted for study and has been identified as occurring and most likely caused by these experiences. Particularly for the first three types of abuse mentioned, PTSD, as a subtype of anxiety disorders, has been identified as a potential and even likely mental health outcome. Studies of shelter populations indicate that a majority of the women report PTSD symptoms (e.g., Kemp et al. 1995), and victims of sexual assault, severe abuse, and those who perceive more threats on their lives are most often identified to develop PTSD (Follingstad 2003). One study reported that women who have been stalked, especially if the tone of the stalking is threatening, have reported symptoms that are consistent with PTSD diagnoses at rates of 73\% (Logan et al. 2006b). Except for threats of harm and sadistic actions implying potential harm, psychological abuse includes many other strategies of domination and control that would not technically qualify as life events (i.e., trauma) capable of producing PTSD. PTSD as a diagnosis is more focused on the development of symptoms following highly fearful and concrete experiences, and includes sequelae that recreate the fear, promote avoidance and withdrawal, and that take the form of overactivation of physiological responses due to triggering of the autonomic nervous system. The diagnosis of PTSD effectively captures the fearfulness resulting from physical battering, sexual assault, and stalking that include the potential of serious harm or death. However, "anxiety" encompasses a broader range of diagnoses and symptoms that need to be assessed for all of the forms of VAW. Comorbidity rates of PTSD have included panic disorders, specific phobias, obsessive-compulsive disorder, and generalized anxiety disorder as occurring at much higher rates for individuals with these types of traumas in their backgrounds (Gleason 1993). Thus, anxiety needs to be more broadly studied across these populations to capture the myriad ways in which anxiety may be manifested. Anxiety also needs to be conceptualized, separate from fear, as a clinical entity that entails psychological threats to one's self-view, whether externally or internally induced. Many forms of psychological maltreatment, such as those designed to denigrate the partner, establish the partner in an inferior position, keep the partner submissive, or prevent the partner from having any power, would seem highly likely to trigger clinical manifestations of anxiety. 
Depression (as a clinical disorder and as symptoms representative of depression) has also been identified across all forms of victimization. IPV has been clearly associated with depression (e.g., Plichta 1996), although shelter samples of women (e.g., Campbell et al. 1997) more frequently demonstrate depression than do community samples of women experiencing IPV. Women who have been sexually assaulted as adults also show higher rates of depression than prevalence rates would predict (e.g., Miller et al. 2005). Stalking victims report depressive symptoms (e.g., Davis et al. 2002), especially when the stalker is an intimate partner (Logan et al. 2006a). Follingstad's (2009a) review suggested that depressive symptoms are the best-documented mental health symptoms related to psychological abuse, but these symptoms are more evident as psychological aggression increases. When women experience physical maltreatment along with psychological aggression the picture becomes much more complicated, and research results are not consistent as to which form of VAW is more likely to predict depression. Not only is there a need for future research to confirm the independent contribution of psychological abuse in the identification of depressive symptoms, but research also needs to establish whether the impact of that form of maltreatment produces depression that is diagnosable as a clinical syndrome. As a subcategory of depression, suicidality seems linked with IPV and sexual assault (e.g., Kernic et al. 2000, McFarlane et al. 2005), but less so for stalking and psychological maltreatment.

Substance use disorders have also been researched for their relationship to women experiencing traumas, and an association has often been found. Researchers have yet to discern the causal direction between experiencing trauma and abusing alcohol and drugs, and a complicated relationship between these is likely to emerge. Women who have been sexually abused, physically abused, or both are more likely to have problematic substance use behaviors and attend treatment programs (e.g., Covington 1997, Miller et al. 1993), and one study ascertained that alcohol and illicit drug use increased for women who experienced multiple assaults (McFarlane et al. 2005). Sexual assault victims often increase substance use following the assault as well (e.g., Campbell et al. 2009). The relationship of substance problems to stalking is not quite as clear. One study (Slashinski et al. 2003) analyzed the NVAWS data focusing on women who were dating and found an association between stalking and recreational drug use, but much more research is required to make any statement about the relationship of substance abuse and the experience of being stalked. Research assessing the association between psychological maltreatment with substance abuse is too sparse, and the few studies available present contradictory findings (Follingstad 2009a). Without longitudinal studies, determining the cause-effect links between VAW and substance problems is likely to remain unsolved.

Beyond diagnoses, other psychological states or traits have been investigated in relation to experiencing VAW. Self-esteem is one such concept that has been considered at risk for harm due to trauma experiences and subsequent coping attempts. This association has been found with IPV victims such that abused women have lower levels of self-esteem than women who are not abused (e.g., Dutton \& Painter 1993). Although lower self-esteem is not an automatic result of experiencing sexual assault, one study found that women who were repeated victims of sexual violence were more likely to have low self-esteem due to selfblaming attributions and believing they had not coped well (Neville et al. 2004). Although one might not predict that self-view would be impacted by events clearly perpetrated by an external source, Logan et al. (2006b) found that $63 \%$ of the women in their study who were victims of stalking reported lower levels of selfesteem due to diminished self-confidence and negative self-perceptions. Thus, similar to victims of sexual assault, self-esteem may be more affected by a woman's assessment of her coping with the trauma as opposed to the form of violence having direct implications for her 
self-view. The few studies assessing self-esteem in relation to psychological abuse suggested that a tentative and not highly predictive relationship existed, and that mediating variables (e.g., the type of psychological aggression directed at the woman, type of coping strategies, initial self-esteem level, self-assessment of coping abilities) are likely to illuminate the impact on self-esteem rather than psychological abuse automatically harming self-concept (Follingstad 2009a).

Whether women who are victims of VAW blame themselves has not been consistently established. Regarding IPV, some researchers have found that women who are abused are not likely to blame themselves, especially when the abuse is frequent and severe (e.g., Frieze 1979). However, some researchers who have studied self-blame in abused women have reported that women who do accept self-blame for the abuse occurring are less likely to end the relationship because they excuse the violence as a function of relationship problems or stressful situations (e.g., Ferraro 1993). Women who receive multiple forms of abuse experience increases in selfblame, due to the difficulty of identifying the cause upon which to place blame (Koss et al. 2002, Logan et al. 2006b). Few studies have assessed the relationship of stalking with selfblame, although one study found that college women who were stalked by an ex-partner experienced higher levels of self-blame than did those women who had been victims of sexual assault or college women who had not been stalked or abused (Kamphuis et al. 2003). Only Street \& Arias (2001) assessed the role of guilt and shame subsequent to experiencing psychological abuse; thus, this potential outcome variable has not been studied enough to suggest an association.

There are certainly other personality traits and emotional states that require investigation to understand more fully the wide-ranging impact of VAW. For example, Briere \& Jordan (2004) have strongly suggested that the effects of physical IPV go far beyond anxiety symptoms and PTSD-related outcomes. They delineate the psychological complexity for women experiencing IPV where the nature of IPV is ongoing and the woman's navigation of a relationship with the person abusing her results in a range of psychological and behavioral difficulties beyond diagnoses. The experiences of sexual assault and stalking also should not be thought of as producing strictly PTSD-related effects in light of the numerous spheres of these victims' lives that are impacted by these traumas. And, because psychological abuse is ongoing, consists of diverse interactions and behaviors over time, and may occur in more reciprocal interactions than other forms of abuse, understanding the effects of this form of maltreatment will also require sophisticated and in-depth investigation. The study of personality traits of interest that could certainly be impacted by interpersonal traumas include sociability, openness to experience, dependency, assertiveness, and trust, while emotional states could incorporate helplessness, anger, alienation, isolation (loneliness), and loss. Changes in beliefs and values (e.g., loss of invulnerability, lack of predictability) are also important effects for further inquiry.

\section{VIOLENCE AGAINST WOMEN AND THE MENTAL HEALTH SYSTEM}

If there is one consistency in reviews of clinical outcome research related to IPV, sexual assault, and other forms of violence against women, it is that the extant literature is inadequate. Significant complexity exists in attempting to measure the effectiveness of interventions, beginning with the fact that, as has been noted, "victimization is not a discrete clinical, social, or legal phenomenon; rather, it is better characterized as a cluster of problems that may include psychiatric, physiological, social, and legal problem areas ... victimization responses also include great diversity in problem severity and complexity, ranging from women with minimal symptoms of distress to women with severe physical and mental health problems and cooccurring substance abuse" (Logan et al. 2006b, p. 134). 
Research also suggests that more than just clinical need affects which victims seek mental health care. Most victims who seek traditional mental health services, for example, are Caucasian (Campbell et al. 2001, Starzynski et al. 2007). Ethnic minority women are more likely to turn to informal sources of support (e.g., friends and family) (Wyatt 1992) and may not necessarily place the same value on formal psychotherapy (Bletzer \& Koss 2006). Victims without health insurance are also significantly less likely to obtain mental health services (Koss et al. 2003, Starzynski et al. 2007). For victims of IPV and stalking in particular, there are abuse-specific barriers to seeking mental health services. Assailants and stalkers may actively try to prevent women from seeking care, and survivors themselves may struggle with whether what they have experienced merits psychological intervention (Liang et al. 2005). There is also research showing that even when women with abuse exposure do enter the mental health care system, they are not always identified as victims (Jordan \& Walker 1994, Lundy \& Grossman 2001). The impact of all of these challenges may be reflected in the finding of a recent review that between $12 \%$ and $50 \%$ of victims of IPV and sexual assault report using counseling or mental health services to cope with the victimization experience (Logan et al. 2006b).

The majority of published reports on interventions with victims of IPV offer theoretical models that are not empirically tested (Johnson \& Zlotnick 2009). Only a handful of evaluation studies met the criteria of a recent review (experimental design; sample size of at least 20 participants; recidivism or measures of violence severity were included as outcome variables) (e.g., McFarlane et al. 2000, Sullivan et al. 1994, Sullivan \& Bybee 1999), and the review found that the support and advocacy services evaluated have short-term impacts that are less effective than mandatory arrest (Stover et al. 2009). Importantly, the usefulness of this review is limited in that recidivism is the primary outcome measure; it does not include mitigation of psychological sequelae, client satisfaction, or other important measures. In randomized control trial treatment outcome studies that are more focused on symptom alleviation (e.g., IPV: Kubany et al. 2004; sexual assault: Resick et al. 2002; stalking: Spence-Diehl 2004), studies suggest that cognitive-behavioral therapies, such as cognitive processing therapy and prolonged exposure, are effective in alleviating PTSD symptoms (Foa et al. 2000).

When victims do receive community-based mental health services, it is unclear whether practitioners are consistently using empirically supported treatments. At least one statewide random-sample study of practitioners suggests it is unlikely. Campbell and colleagues' (1999a) survey of licensed mental health professionals in a Midwestern state found that most (52\%) reported using cognitive-behavioral methods with victims of violence of IPV and/or sexual assault, but almost all practitioners stated they rarely use a single approach and intentionally combine multiple therapeutic orientations and treatments.

Few studies have examined if and how victims benefit from community-based mental health services. In general, victims tend to rate their experiences with mental health professionals positively and characterize their help as useful and supportive (Campbell et al. 2001; Ullman 1996a,b). Whether positive satisfaction results in demonstrable mental health benefit is largely unknown, although community-based mental health services were particularly helpful for sexual assault survivors who had had negative experiences with the legal and/or medical systems. Victims who encountered substantial difficulty obtaining needed services and experienced substantial victim blaming from legal and medical system personnel had high PTSD symptomatology; but among this high-risk group of survivors, those who had been able to obtain mental health services had significantly lower PTSD, suggesting that there may have been some benefit from receiving such services. In this same sample, however, $25 \%$ of women who received postassault mental health services rated this 
contact as hurtful (with 19\% characterizing it as severely hurtful) (Campbell et al. 2001).

In the area of IPV, the most commonly utilized modality of clinical intervention for general population samples appears to be group work (Tutty et al. 1993). Although the literature on the efficacy of this approach is limited, most studies suggest that the unstructured approach of these groups and their focus on emotional processing lead to client gains (Tutty et al. 1993) and that their psychoeducational nature provides a mechanism by which women can learn about the dynamics of abusive relationships, parenting skills, assertiveness skills, and anger management (Dutton 1992).

Victims also obtain mental health services in specialized VAW agencies, such as domestic violence shelter programs and rape crisis centers. These agencies help victims negotiate their contact with the legal and medical systems, and they also provide individual and group counseling (Campbell \& Martin 2001). They offer critical protective services for women, but a review suggests that only a small percentage $(3 \%-21 \%)$ utilize their services (Logan et al. 2006b). Little is known about the therapeutic orientations and treatment approaches used in domestic violence shelter programs and rape crisis centers, but current data indicate a strong feminist and/or empowerment theoretical orientation (e.g., shared goal setting, focus on gender inequalities, identification of VAW not only as a personal problem but also as a social problem) (Edmond 2006, Goodman $\&$ Epstein 2008). In a national survey of domestic violence shelters and rape crisis centers, approximately $70 \%$ of the agencies reported using cognitive-behavioral methods in combination with other methods (e.g., clientcentered and feminist) (Edmond 2006). With respect to counseling outcomes, a statewide evaluation project in Illinois compared selfreported PTSD symptoms pre- and postcounseling among victims receiving counseling services through domestic violence shelters/rape crisis centers, and found significant reductions in distress levels and self-blame over time and increases in social support, self efficacy, and sense of control (Bennett et al. 2004). Because this project did not examine the content of services or include comparison groups, it is unclear whether these observed improvements are attributable to the services provided. Research suggests that mobilizing resources to respond to victims' immediate needs and linking them to services in the community as is provided in shelter settings have been found to reduce distress and increase long-term quality of life for abuse survivors (see Sullivan \& Bybee 1999).

To date, a limited number of projects have focused on developing empirically supported treatments for use in domestic violence shelters (or during the transitional period for women postshelter exit). Sullivan and colleagues experimentally evaluated a postshelter intervention that provided 10 weeks of social support and advocacy to help women mobilize resources and link them to services in the community. This intervention did not provide therapeutic/counseling services, but at twoyear follow-up, women in the experimental condition had significantly lower levels of psychological distress and increased long-term quality of life in comparison with women the control condition (see Sullivan \& Bybee 1999). Similarly, Constantino et al.'s (2005) in-shelter social support intervention was successful in reducing mental health distress and health care utilization among women in the experimental condition. More recently, Johnson \& Zlotnick (2006, 2009) evaluated an in-shelter, cognitive behavioral treatment program for PTSD symptomatology among battered women (project HOPE). Although this study did not use a true experimental design (intent-to-treat clients were compared to treatment completers), their results were quite encouraging such that women who received HOPE demonstrated statistically and clinically significant decreases in PTSD, depression, and social impairment. These positive effects persisted up to six months postshelter, but these results merit replication with a stronger evaluation design. The dearth of research in this area clearly indicates a pressing need for the 
development of effective treatment programs that can be used with women on site in rape crisis centers and domestic violence shelters.

\section{STATE OF VIOLENCE AGAINST WOMEN AS A FIELD OF RESEARCH}

Thirty years ago, the most visible presence of a field of VAW was found in battered women's shelters, rape crisis centers, courthouses, police stations, and hospital emergency rooms, where advocates and other professionals worked to intervene, protect, and repair the damage violence had inflicted on the lives of women and children. Over time, the VAW field also moved to capitol buildings and state houses, where laws were changed and policies adopted to address VAW. A field of research on VAW has also existed for over three decades, its historical roots incubated in a social justice belief that research must lead to understanding VAW, not for the sake of scientific exploration alone, but with the goal of ending the systematic battering and killing of women (e.g., Brownmiller 1975; Dobash \& Dobash 1979; Martin 1976; Russell 1974, 1982; Schechter 1982).

Although the work of multidisciplinary scholars has contributed enormously to our understanding of the etiology, context, and impact of various forms of VAW, critiques of the past ten years have repeatedly noted that weaknesses in the field limit a full scientific exploration of these crimes and their effects. In 1994, a panel brought together by the National Research Council concluded that "significant gaps exist in understanding the extent and causes of VAW and the impact and effectiveness of preventive and treatment interventions" (Crowell \& Burgess 1996, p. 2). Key weaknesses in the field include the fact that types of abuse tend to be studied as distinct subdivisions in the VAW field, such that researchers study sexual violence, physical violence, stalking, psychological aggression, and other abuse forms in a silo pattern. While a narrow focus in research can lend itself to a more rich understanding of any single phenomenon, in the VAW field that approach also carries with it the risk that a woman's experience is seen out of context and does not reflect the fact that most often different forms of abuse occur concurrently in the life of a woman (Crowell \& Burgess 1996, Jordan 2009). There has also been a separation between VAW-related research and research in broader areas of study, including psychology and sociology/criminology. Although the multidisciplinary nature of the field is a strength and critical to the field's ability to provide mental health, health care, and other services to women and their children, on the research side, that character has also brought challenges. Different disciplines operate with their own theoretical models, methodological approaches, and pedagogies, and they rely on their own literatures, making collaborative work and generalizability of studies more complex. Other methodological challenges (e.g., inconsistencies in operational definitions of abuse used in the literature; lack of theory and of longitudinal studies; a need to integrate datasets; the extra challenge of safety as a human subjects issue) and insufficient federal funding for research on VAW have also been chronicled by numerous authors (Campbell et al. 2006, Crowell \& Burgess 1996, Ford et al. 2002, Koss 2005, Koss \& White 2008, Kruttschnitt et al. 2002, Jordan 2009, Richie 1996).

In part, weaknesses in the extant research field reflect the youth of the field, the architecture of universities that are divided by discipline and department, and the way in which research has been approached. The phenomenon itself, however, also brings challenges to any scientist. As noted by Jordan (2009, pp. 394-95):

VAW-research is enormously challenging. The magnitude and impacts noted above tax research capabilities, but it is more complex yet. The quality of the experience of victimization is different for women; first because no one set of behaviors comprises the experience, victims experience different levels of severity, chronicity, and most face multiple types of abuse (Campbell \& Soeken 1999, Coker et al. 2000, Riggs et al. 1992). Victims 
also define those experiences differently, in some cases influenced by the effects of historic exposure to abuse (Briere 1996, Desai et al. 2002) or because they live in a culture that defines or acknowledges abuse in a unique way (Cousineau \& Rondeau 2004, Kasturirangan et al. 2004). There is also no single health or mental health presentation of abuse and no standard sequelae for reacting to it (Banyard et al. 2001, Briere \& Jordan 2004, Charney 2004). It is difficult further because of the heterogeneity of stalkers, IPV offenders and sex offenders (Davis \& Chipman 2001, Holtzworth-Munroe \& Meehan 2004, Robertiello \& Terry 2007).

Strengthening research in the area of VAW will require significant reforms. Increases in federal funding, improvements in methodologies, the development of a more cohesive community of scientists from multiple disciplines, a stronger infrastructure within academia (including creation of additional interdisciplinary research centers), and other improvements are needed. Some have called for a model that would (a) establish a new area of science as a means to make the greatest advancements, a dramatic step that would improve the field's organization of knowledge; (b) set forth a structure by which testing and retesting and the generation of theory would more readily occur; (c) facilitate development of pedagogy for the transmission of information on VAW to future researchers; $(d)$ strengthen the organization of the written literature in textbooks and bibliographic databases; and (e) carve a place for practitioners and advocates on collaborative research teams (Jordan 2009). The challenge of such a model may be found less in the practical changes needed to accomplish it as in the difficulties developing the kind of science necessary to make significant contributions to both understanding and ending VAW (Campbell 2009).

\section{CONCLUSION}

As has been noted in this review, the reach of VAW has been felt by women across the United States and around the globe. Studies make clear that the impact of IPV, stalking, rape, and psychological aggression on women's mental health is robust, although women do not experience these negative psychological health effects in the same time frame or to the same extent. The complexities of the various forms of VAW and of postassault responses by the women who experience them make both clinical intervention and outcome research challenging. As the clinical and research fields progress in addressing VAW, it is clear that the discipline of psychology has the opportunity play a leadership role. As noted in a recent review (Jordan 2009), although VAW-related scholarship of the past three decades represents the contributions of an interdisciplinary group of scholars, psychology is the most commonly cited discipline in the VAW field. By offering the structure of its clinical training programs, psychological theory, rigorous research methodologies, and other strengths, the discipline of psychology has an opportunity to advance research on VAW, to mitigate its harm, and to contribute to bringing these traumatic phenomena to an end.

\section{SUMMARY POINTS}

1. Violence against women (VAW) is a substantial mental health concern. Research suggests that the effects of intimate partner violence (IPV), stalking, rape, and psychological aggression on women's mental health are significant, and in fact, most forms of major nonorganic mental distress and disorder have been associated with violence against women. 
2. VAW is not a single, discrete phenomenon. It has now been documented to occur in multiple forms, including physical assault, sexual assault, stalking, and psychological aggression.

3. Across populations of women experiencing IPV, sexual assault, stalking, or psychological abuse, anxiety has been identified as occurring and most likely caused by these experiences. Particularly for the first three types of abuse mentioned, posttraumatic stress disorder, as a subtype of anxiety disorders, has been identified as a potential and even likely mental health outcome.

4. Depression (as a clinical disorder and as symptoms representative of depression) has also been identified across all forms of victimization. Substance use disorders have also been researched for their relationship to women experiencing traumas, and an association has often been found. Researchers have yet to discern the causal direction between experiencing trauma and abusing alcohol and drugs, and a complicated relationship between these is likely to emerge.

5. The extant clinical outcome research related to IPV, sexual assault, and other forms of violence against women is inadequate.

6. A field of research on VAW has existed for 30 years, its historical roots incubated in a social justice belief that research must lead to understanding VAW, not for the sake of scientific exploration alone, but with the goal of ending the experience for women.

7. Although the work of multidisciplinary scholars has contributed enormously to our understanding of the etiology, context, and impact of various forms of VAW, critiques of the past 10 years have repeatedly noted that weaknesses in the field limit a full scientific exploration of these crimes and their effects.

8. Strengthening research in the area of VAW will require significant reforms. Increases in federal funding, improvements in methodologies, the development of a more cohesive community of scientists from multiple disciplines, a stronger infrastructure within academia (including creation of additional interdisciplinary research centers), and other improvements are needed. Some have called for the establishment of a new area of science as a means to make the greatest advancements, a dramatic step that would improve the field's organization of knowledge; set forth a structure by which testing and retesting and the generation of theory would more readily occur; facilitate development of pedagogy for the transmission of information on VAW to future researchers; strengthen the organization of the written literature in textbooks and bibliographic databases; and carve a place for practitioners and advocates on collaborative research teams.

\section{DISCLOSURE STATEMENT}

The authors are not aware of any affiliations, memberships, funding, or financial holdings that might be perceived as affecting the objectivity of this review.

\section{ACKNOWLEDGMENT}

The authors thank Giannina Cabral, Katie Gregory, Melissa Riddle, and Jill Rogers for their assistance with preparation of this manuscript. 


\section{LITERATURE CITED}

Aldaronda E, Kantor G, Jasinski J. 2002. A risk marker analysis of wife assault in Latino families. Violence Against Women 8(4):429-54

Bachman R, Saltzman L. 1995. Violence Against Women: Estimates from the Redesigned Survey. Washington, DC: U.S. Dept. Justice, Bur. Justice Stat.

Bachar K, Koss MP. 2001. From prevalence to prevention: closing the gap between what we know about rape and what we do. In Sourcebook on Violence Against Women, ed. CM Renzetti, JL Edleson, RK Bergen, pp. 117-42. Thousand Oaks, CA: Sage

Banyard V, Williams L, Siegel J. 2001. The long-term mental health consequences of child sexual abuse: an exploratory study of the impact of multiple traumas in a sample of women. F. Trauma. Stress 14:697-715

Basile KC, Saltzman LE. 2002. Sexual Violence Surveillance: Uniform Definitions and Recommended Data Elements. Atlanta, GA: Cent. Disease Control Prev.

Bennett L, Riger S, Schewe P, Howard A, Wasco S. 2004. Effectiveness of hotline, advocacy, counseling, and shelter services for victims of domestic violence: a statewide evaluation. 7. Interpers. Violence 19(7):815-29

Bent-Goodley T. 2001. Eradicating domestic violence in the African American community: a literature review and action agenda. Trauma Violence Abuse 2:316-30

Berger RJ, Searles P, Neuman WL. 1988. The dimensions of rape reform legislation. Law Soc. Rev. 22:329-57

Bletzer KV, Koss MP. 2006. After rape among three populations in the Southwest: a time for mourning, a time for recovery. Violence Against Women 12(1):5-29

Briere J. 1996. Therapy for Adults Molested as Children. New York: Springer. 2nd ed.

Briere J, Jordan CE. 2004. Violence against women: outcome complexity and implications for treatment. 7. Interpers. Violence 19(12):1252-82

Briere J, Woo R, McRae B, Foltz J, Sitzman R. 1997. Lifetime victimization history, demographics, and clinical status in female psychiatric emergency room patients. 7. Nerv. Ment. Dis. 185:95-101

Brownmiller S. 1975. Against Our Will: Men, Women, and Rape. New York: Bantam

Bubar R, Thurman PJ. 2004. Violence against Native women. Soc. Fustice 31(4):70-86

Campbell JC, Kub J, Belknap RA, Templin TN. 1997. Predictors of depression in battered women. Violence Against Women 3:271-93

Campbell JC, Martin S, Moracco K, Manganello J, Macy R. 2006. Survey data sets pertinent to the study of intimate partner violence and health. Trauma Violence Abuse 7(1):3-18

Campbell JC, Soeken K. 1999. Forced sex and intimate partner violence: effects on women's risk and women's health. Violence Against Women 5:1017-35

Campbell JC, Sullivan CM, Davidson WS. 1995. Depression in women who use domestic violence shelters: a longitudinal analysis. Psychol. Women Q. 19:237-55

Campbell JC, Webster D, Koziol-McLain J, Block C, Campbell D, et al. 2003. Risk factors for femicide in abusive relationships: results from a multisite case control study. Am. F. Public Health 93(7):1089-97

Campbell R. 2009. Science, social change, and ending violence against women. Violence Against Women 15(4):434-39

Campbell R, Dworkin E, Cabral G. 2009. An ecological model of the impact of sexual assault on women's mental health. Trauma Violence Abuse 10(3):225-46

Campbell R, Martin PY. 2001. Services for sexual assault survivors: the role of rape crisis centers. In Sourcebook on Violence Against Women, ed. C Renzetti, J Edleson, R Bergen, pp. 227-41. Thousand Oaks, CA: Sage

Campbell R, Raja S, Grining PL. 1999a. Training mental health professionals on violence against women. 7. Interpers. Violence 14(10):1003-13

Campbell R, Sefl T, Barnes HE, Ahrens CE, Wasco SM, Zaragoza-Diesfeld Y. 1999b. Community services for rape survivors: enhancing psychological well-being or increasing trauma? 7 . Consult. Clin. Psychol. 67(6):847-58

Campbell R, Wasco SM, Ahrens CE, Sefl T, Barnes HE. 2001. Preventing the "second rape”: rape survivors' experiences with community service providers. F. Interpers. Violence 16(12):1239-59

Charney D. 2004. Psychobiological mechanisms of resilience and vulnerability: implications for successful adaptation to extreme stress. Am. F. Psychiatry 161:195-216
Using an ecological theoretical perspective, the authors investigate the influence of adult sexual assault on postassault sequelae and survivor's mental health. Self-blame is highlighted as an important construct that is derived from all levels of Brofenbrenner's ecological theory of human development. 
Reviews the current methods through which psychological abuse has been described, validated, or conceptualized. Authors make recommendations for the inclusion of alternative variables in this construct.
Coker A, Smith P, Bethea L, King M, McKeown R. 2000. Physical health consequences of physical and psychological intimate partner violence. Arch. Fam. Med. 9:451-57

Constantino R, Kim Y, Crane PA. 2005. Effects of a social support intervention on health outcome in residents of a domestic violence shelter: a pilot study. Iss. Mental Health Nurs. 26(6):575-90

Covington S. 1997. Women, addiction, and sexuality. In Gender and Addictions: Men and Women in Treatment, ed. SLA Straussner, E Zelvin, pp. 71-96. Northvale, NJ: Aronson

Cousineau M, Rondeau G. 2004. Toward a transnational and cultural analysis of family violence: issues and recommendations. Violence Against Women 10(8):935-49

Crowell N, Burgess A. 1996. Understanding Violence Against Women. Washington, DC: Nat. Acad. Press

Davis J, Chipman M. 2001. Stalkers and other obsessional types: a review and forensic psychological typology of those who stalk. In Stalking Crimes and Victim Protection: Prevention, Intervention, Threat Assessment, and Case Management, ed. JA Davis, pp. 3-18. Boca Raton, FL: CRC Press

Davis KE, Coker AL, Sanderson M. 2002. Physical and mental health effects of being stalked for men and women. Violence Vict. 17(4):429-43

Desai S, Arias I, Thompson M, Basile K. 2002. Childhood victimization and subsequent adult revictimization assessed in a national representative sample of women and men. Violence Vict. 17:639-53

Dobash RE, Dobash R. 1979. Violence Against Wives. New York: Free Press

Dutton DG, Painter S. 1993. The battered woman syndrome: the effects of severity and intermittency of abuse. Am. 7. Orthopsychiatry 63:614-22

Dutton MA. 1992. Empowering and Healing the Battered Women: A Model for Assessment and Intervention. New York: Springer

Dutton MA, Goodman L, Bennett L. 1999. Court-involved battered women's responses to violence: the role of psychological, physical, and sexual abuse. Violence Vict. 14:89-104

Edmond T. 2006. Theoretical and intervention preferences of service providers addressing violence against women: a national survey. Presented at Council Soc. Work Ed. Conf., Chicago

Ferraro K. 1993. Rationalizing violence: how battered women stay. Victimology 8:203-12

Fiol EG, Perez VA. 2004. Battered women: analysis of demographic, relationship and domestic violence characteristics. Psychol. Spain 8:3-15

Fisher BS. 2001. Being pursued and pursuing during the college years: the extent, nature, and impact of stalking on college campuses. In Stalking Crimes and Victim Protection: Prevention, Intervention, Threat Assessment, and Case Management, ed. JA Davis, pp. 207-38. Boca Raton, FL: CRC Press

Foa EB, Keane TM, Friedman MJ. 2000. Effective Treatments for PTSD: Practice Guidelines from the International Society for Traumatic Stress Studies. New York: Guilford. 643 pp. 2nd ed.

Follingstad DR. 2003. Battered Woman Syndrome in the courts. In Handbook of Psychology: Volume 11, Forensic Psychology, ed. AM Goldstein, IB Weiner, pp. 485-507. Hoboken, NJ: Wiley

Follingstad DR. 2007. Rethinking current approaches to psychological abuse: conceptual and methodological issues. Aggression Violent Behav. 12:439-58

Follingstad DR. 2009a. Psychological aggression and women's mental health: the status of the field. Trauma Violence Abuse 10(3):271-89

Follingstad DR. 2009b. A measure of severe psychological abuse normed on a nationally representative sample. 7. Interpers. Violence. Manuscr. submitted

Follingstad DR, DeHart DD. 2000. Defining psychological abuse of husbands toward wives: contexts, behaviors, and typologies. 7. Interpers. Violence 15:891-920

Follingstad DR, Helff CM, Binford RV, Runge MM, White JD. 2004. Lay persons' versus psychologists' judgments of psychologically aggressive actions. 7. Interpers. Violence 19:916-42

Follingstad D, Rutledge L, Berg B, Hause E, Polek D. 1990. The role of emotional abuse in physically abusive relationships. 7. Interpers. Violence 15:891-920

Ford DA, Bachman R, Friend M, Meloy M. 2002. Controlling Violence Against Women: A Research Perspective on the 1994 VAWA's Criminal fustice Impacts. Washington, DC: Nat. Inst. Justice, U.S. Dep. Justice

Frieze IR. 1979. Perceptions of battered women. In New Approaches to Social Problems, ed. IR Frieze, D Bar-Tal, VS Carroll, pp. 79-108. San Francisco: Jossey-Bass

Gauge AJ, Hutchinson PL. 2006. Power, control and intimate partner sexual violence in Haiti. Arch. Sex. Behav. 35(1):11-24 
Gleason W. 1993. Mental disorders in battered women: an empirical study. Violence Victims 8:53-68

Goodman LA, Epstein D. 2008. Listening to Battered women: A Survivor-Centered Approach to Advocacy, Mental Health, and fustice. Washington, DC: Am. Psychol. Assoc. 184 pp.

Goodman LA, Salyers MP, Mueser KT, Rosenberg SD, Swartz M, et al. 2001. Recent victimization in women and men with severe mental illness: prevalence and correlates. F. Trauma Stress 14(4):615-32

Grant B, Harford T, Dawson D, Chou P, Dufour M, Pickering R. 1994. Prevalence of DSM-IV alcohol abuse and dependence: United States 1992. Alcohol Health Res. World 18(3):243-48

Greenfeld L, Rand M, Craven D, Klaus PA, Perkins CA, et al. 1998. Violence by Intimates: Analysis of Data on Crimes by Current or Former Spouses, Boyfriends, and Girlfriends (NCF-167237). Washington, DC: Bur. Justice Stat., U.S. Dep. Justice

Herman JL. 1992. Complex PTSD: A syndrome in survivors of prolonged and repeated trauma. 7. Trauma Stress 5(3):377-91

Holtzworth-Munroe A, Meehan J. 2004. Typologies of men who are maritally violent: scientific and clinical implications. F. Interpers. Violence 19(12):1369-89

Janoff-Bulman R. 1992. Shattered Assumptions: Towards a New Psychology of Trauma. New York: Free Press

Jewkes R, Sen P, Garcia-Moreno C. 2002. Sexual violence. In World Report of Violence and Health, ed. E Krug, L Dahlberg, JA Mercy, AB Zwi, R Lozano, pp. 147-74. Geneva, Switzerland: World Health Org.

Johnson DM, Zlotnick C. 2006. A cognitive-behavioral treatment for battered women with PTSD in shelters: findings from a pilot study. F. Trauma Stress 19(4):559-64

Johnson DM, Zlotnick C. 2009. HOPE for battered women with PTSD in domestic violence shelters. Prof. Psycbol. Res. Pract. 40(3):234-41

Jones JH, Ferguson B. 2009. Demographic and social predictors of intimate partner violence in Colombia: a dyadic power perspective. Hum. Nat. 20:184-203

Jordan CE. 2009. Advancing the study of violence against women: evolving research agendas into science. Violence Against Women 15(4):393-419

Jordan CE, Nietzel MT, Walker R, Logan TK. 2004. Intimate Partner Violence: A Clinical Training Guide for Mental Health Professionals. New York: Springer

Jordan CE, Quinn K, Jordan B, Daileader CR. 2000. Stalking: cultural, clinical and legal considerations. Brandeis 7. Family Law 38(3):513-79

Jordan CE, Walker R. 1994. Implementing domestic violence standards of practice for community mental health centers. Hosp. Commun. Psychiatry 45(2):147-51

Jordan CE, Wilcox P, Pritchard A. 2007. Stalking acknowledgment and reporting among college women experiencing intrusive behaviors: implications for the emergence of a "classic stalking case." 7 . Crim. Fustice 35(5):556-69

Kamphuis JH, Emmelkamp PMG, Bartak A. 2003. Individual differences in post-traumatic stress following postintimate stalking: stalking severity and psychosocial variables. Br. F. Clin. Psychol. 42:145-56

Kasturirangan A, Krishnan S, Riger S. 2004. The impact of culture and minority status on women's experience of domestic violence. Trauma Violence Abuse 5(4):318-32

Kemp A, Green BL, Hovanitz C, Rawlings EI. 1995. Incidence and correlates of posttraumatic stress disorder in battered women: shelter and community samples. F. Interpers. Violence 10:43-55

Kernic M, Wolf M, Holt V. 2000. Rates and relative risk of hospital admission among women in violent intimate partner relationships. Am. F. Publ. Health 90:1416-20

Kilpatrick DG, Acierno R, Resnick HS, Saunders BE, Best CL. 1997. A 2-year longitudinal analysis of the relationships between violent assault and substance use in women. F. Consult. Clin. Psychol. 65:834-47

Koss MP. 2005. Empirically enhanced reflection on 20 years of rape research. 7. Interpers. Violence 20:100-7

Koss MP, Achilles M. 2008. Restorative justice responses to sexual assault. http://www.vawnet.org

Koss MP, Bailey JA, Yuan NP, Herrera VM, Lichter EL. 2003. Depression and PTSD in survivors of male violence: research and training initiatives to facilitate recovery. Psychol. Women Q. 27(2):130 42

Koss MP, Figueredo AJ. 2004. Cognitive mediation of rape's mental health impact: constructive replication of a cross-sectional model in longitudinal data. Psychol. Women Q. 28(4):273-86

Koss MP, Figueredo A, Prince R. 2002. Cognitive mediation of rape's mental, physical, and social health impact: tests of four models in cross-sectional data. F. Consult. Clin. Psychol. 70:926-41
Combines and integrates the current literature regarding intimate partner violence victims, offenders, and child witnesses to supply clinicians with advice for aiding clients who have survived these situations.

Investigates the mental health effects of male violence on women, concentrating on depression and PTSD. Mental health services for this population are also reviewed. 
Examines the effectiveness of cognitive trauma therapy for battered women with posttraumatic stress disorder. Decreased PTSD symptoms were reported by $87 \%$ of women, and these improvements were sustained at 3- and 6-month follow-ups.

Provides an inclusive review of the literature available regarding violence against women and the contributing factors, interventions, and implications. The authors integrate and analyze the existing research.
Koss MP, White JW. 2008. National and global agendas on violence against women: historical perspective and consensus. Am. F. Orthopsychiatry 78:386-93

Kruttschnitt C, McLaughlin B, Petrie C. 2002. Advancing the Federal Research Agenda on Violence Against Women. Washington, DC: Nat. Acad. Press

Kubany ES, Hill EE, Owens JA, Iannce-Spencer C, McCaig MA, et al. 2004. Cognitive trauma therapy for battered women with PTSD (CTTBW). F. Consult. Clin. Psychol. 72(1):3-18

Kubany ES, Leisen MB, Kaplan AK, Kelly M. 2000. Validation of the Distressing Event Questionnaire (DEQ): a brief diagnostic measure of posttraumatic stress disorder. Psychol. Assess. 12:192-209

Liang B, Goodman L, Tummala-Narra P, Weintraub S. 2005. A theoretical framework for understanding helpseeking processes among survivors of intimate partner violence. Am. F. Commun. Psychol. 36(1-2):71-84

Logan TK, Cole J, Shannon L, Walker R. 2006a. Partner Stalking: How Women Respond, Cope, and Survive. New York: Springer

Logan TK, Walker R, Jordan CE, Leukefeld C. 2006b. Women and Victimization: Contributing Factors, Interventions, and Implications. Washington, DC: Am. Psychol. Assoc.

Lundy M, Grossman S. 2001. Clinical research and practice with battered women: what we know, what we need to know. Trauma Violence Abuse 2(2):120-41

Maiuro RD. 2001. Sticks and stones may break my bones, but names will also hurt me: psychological abuse in domestically violent relationships. In Psychological Abuse in Violent Domestic Relations, ed. KD O'Leary, RD Maiuro, pp. ix-xx. New York: Springer

Markward MJ. 1996. Characteristics of sheltered women and intimates in sexually and nonsexually abusive relationships. Fam. Ther. 23:59-67

Martin D. 1976. Battered Wives. New York: Pocket Books

McCauley J, Kern D, Kolodner K, Dill L, Schroeder A, et al. 1995. The "battering syndrome": prevalence and clinical characteristics of domestic violence in primary care internal medicine practices. Ann. Intern. Med. 123(10):744-81

McFarlane J, Malecha A, Watson K, Gist J, Batten E, et al. 2005. Intimate partner sexual assault against women: frequency, health consequences, and treatment outcomes. Obstet. Gynecol. 105(1):99-108

McFarlane J, Soeken K, Wiist W. 2000. An evaluation of interventions to decrease intimate partner violence to pregnant women. Public Health Nurs. 17:443-51

Miller B, Downs W, Testa M. 1993. Interrelationships between victimization experiences and women's alcohol/drug use. 7. Stud. Alcohol 11:109-17

Miller B, Monson B, Norton M. 2005. The effects of forced sexual intercourse on white female adolescents. Child Abuse Negl. 19:1289-301

Murphy CM, Cascardi M. 1993. Psychological aggression and abuse in marriage. In Family Violence: Prevention and Treatment, Vol. 1, ed. RL Hampton, TP Gullotta, GR Adams, EH Potter III, RP Weissberg, pp. 86112. Newbury Park, CA: Sage

Nat. Criminal Justice Assoc. 1993. Project to Develop a Model Antistalking Code for State. Washington, DC: U.S. Dep. Justice

Neville H, Heppner M, Oh E, Spanierman L, Clark M. 2004. General and culturally specific factors influencing black and white rape survivors' self-esteem. Psychol. Women Q. 28:83-94

O'Donnell CJ, Smith A, Madison JR. 2002. Using demographic risk factors to explain variations in the incidence of violence against women. F. Interpers. Violence 17:1239-62

Palarea R, Zona M, Lane J, Langhinrichsen-Rohling J. 1999. The dangerous nature of stalking: threats, violence and associated risk factors. Behav. Sci. Law 17:269-83

Pathé M, Mullen P. 1997. The impact of stalkers on their victims. Br. F. Psychiatry 170:12-17

Plichta SB. 1996. Violence and abuse: implications for women's health. In Women's Health: The Commonwealth Fund Survey, ed. M Falik, K Collins, pp. 238-70. Baltimore, MD: Johns Hopkins Univ. Press

Plichta SB, Weisman CS. 1995. Spouse or partner abuse, use of health services, and unmet need for medical care in U.S. women. 7. Women's Health 4:45-53

Resick PA, Nishith P, Weaver TL, Astin MC, Feuer CA. 2002. A comparison of cognitive-processing therapy with prolonged exposure and a waiting condition for the treatment of chronic posttraumatic stress disorder in female rape victims. F. Consult. Clin. Psychol. 70(4):867-79 
Richie BE. 1996. Compelled to Crime: The Gender Entrapment of Battered Black Women. New York: Rutledge

Riggs D, Kilpatrick D, Resnick H. 1992. Long-term psychological distress associated with marital rape and aggravated assault: a comparison to other crime victims. F. Family Violence 7:283-96

Robertiello G, Terry K. 2007. Can we profile sex offenders? A review of sex offender typologies. Aggression Violent Behav. 12:508-18

Russell DEH. 1974. The Politics of Rape: The Victim's Perspective. New York: Stein \& Day

Russell DEH. 1982. Rape in Marriage. New York: Macmillan

Schechter S. 1982. Women and Male Violence: The Visions and Struggles of the Battered Women's Movement. Boston: South End Press

Slashinski M, Coker A, Davis K. 2003. Physical aggression, forced sex, and stalking victimization by a dating partner: an analysis of the National Violence Against Women Survey. Violence Victims 18:595-617

Smith PH, Thornton GE, DeVellis R, Earp J, Coker AL. 2002. A population-based study of the prevalence and distinctiveness of battering, physical assault, and sexual assault in intimate relationships. Violence Against Women 8:1208-32

Spence-Diehl E. 2004. Intensive case management for victims of stalking: a pilot test evaluation. Brief Treat. Crisis Intervent. 4(4):323-41

Spitzberg B, Nicastro A, Cousins A. 1998. Exploring the interactional phenomenon of stalking and obsessive relational intrusion. Commun. Rep. 11(1):33-48

Starzynski LL, Ullman SE, Townsend SM, Long DM, Long SM. 2007. What factors predict women's disclosure of sexual assault to mental health professionals? F. Commun. Psychol. 35(5):619-38

Stover CS, Meadows AL, Kaufman J. 2009. Interventions for intimate partner violence: review and implications for evidence-based practice. Prof. Psychol. Res. Pract. 40(3):223-33

Straus MA, Gelles R. 1990. Physical Violence in American Families: Risk Factors and Adaptation to Violence in 8145 Families. New Brunswick, NJ: Transaction Books

Straus MA, Gelles R, Steinmetz S. 1980. Behind Closed Doors: Violence in the American Family. Garden City, NY: Anchor Press

Street AE, Arias I. 2001. Psychological abuse and PTSD in battered women: examining the roles of shame and guilt. Violence Victims 16:65-78

Sullivan CM, Bybee D. 1999. Reducing violence using community-based advocacy for women with abusive partners. F. Consult. Clin. Psychol. 67(1):43-53

Sullivan CM, Campbell R, Angelique H, Eby K, Davidson W. 1994. An advocacy intervention program for women with abusive partners: six-month follow-up. Am. F. Commun. Psychol. 22:101-22

Thompson MP, Kaslow NJ, Kingree JB. 2002. Risk factors for suicide attempts among African American women experiencing recent intimate partner violence. Violence Victims 17:283-95

Tjaden P, Thoennes N. 1998. Stalking in America: Findings from the National Violence Against Women Survey. Washington, DC: U.S. Dep. Justice, Nat. Inst. Justice

Tjaden P, Thoennes N. 2000. Prevalence and consequences of male-to-female and female-to-male intimate partner violence as measured by the National Violence Against Women Survey. Violence Against Women 6(2):142-61

Tjaden P, Thoennes N, Allison CJ. 2000. Comparing stalking victimization from legal and victim perspectives. Violence Victims 15(1):7-22

Tutty LM, Bidgood BA, Rothery MA. 1993. Support groups for battered women: research on their efficacy. 7. Family Violence 8(4):325-43

Ullman SE. 1996a. Do social reactions to sexual assault victims vary by support provider? Violence Victims 11(2):143-56

Ullman SE. 1996b. Correlates and consequences of adult sexual assault disclosure. F. Interpers. Violence 11(4):554-71

Ullman SE, Brecklin LR. 2003. Sexual assault history and health-related outcomes in a national sample of women. Psychol. Women Q. 27:46-57

Weinbaum Z, Stratton TL, Chavez G, Motylewski-Link C, Barrera N, Courtney JG. 2001. Female victims of intimate partner physical domestic violence (IPP-DV), California 1998. Am. F. Prev. Med. 21:313-19

Wyatt GE. 1992. The sociocultural context of African American and white American women's rape. F. Soc. Issues 48(1):77-91
Investigates the occurrence and effects of intimate partner violence. Compares males and females and marital and opposite-sex cohabitating partners. Results indicate that women reported significantly more intimate partner violence than did males. 
Xu X, Campbell J, Zhu F. 2001. Intimate partner violence against Chinese women: the past, present, and future. Trauma Violence Abuse 2(4):296-315

Yoshihama M. 1999. Domestic violence against women of Japanese descent in Los Angeles: two methods of estimating prevalence. Violence Against Women 5(8):869-97

Yoshihama M. 2000. Reinterpreting strength and safety in a socio-cultural context: dynamics of domestic violence and experience of women of Japanese descent. Child. Youth Serv. Rev. 22(3/4):207-29

Yuan NP, Koss MP, Polacca M, Goldman D. 2006. Risk factors for physical assault and rape among six Native American tribes. F. Interpers. Violence 21(12):1566-90 